\title{
A representação do acusativo anafórico de terceira pessoa em contexto escolar: diagnose e proposta
}

\author{
Monique Débora Alves de Oliveira Lima (UFRJ)* \\ https://orcid.org/0000-0001-6980-6836
}

\section{Resumo:}

Neste artigo, apresenta-se uma análise diagnóstica realizada acerca da retomada do acusativo anafórico, em redações de alunos do $6^{\circ}$ e 9o anos do Ensino Fundamental de uma escola de rede municipal de ensino do Rio de Janeiro. Ancorada na Sociolinguística Variacionista (WEINREICH; LABOV; HERZOG, 2006 [1968]; LABOV, 2008 [1972]), a investigação parte do pressuposto de que a língua é variável e há, portanto, formas distintas com mesmo valor representacional para expressar o acusativo anafórico de terceira pessoa. A partir da análise diagnóstica realizada, propôs-se um material didático destinado a alunos do 9o em diante, que se prestasse ao ensino de pronomes - dentre os quais as estratégias de retomada do acusativo anafórico de terceira pessoa - no âmbito escolar. Para a elaboração do material didático, tomou-se como base a proposta de Ensino de Gramática em Três Eixos de VIEIRA (2017). A investigação ora desenvolvida busca contribuir tanto com as reflexões sobre o ensino de Língua Portuguesa quanto com efetivas propostas para ensino de fenômenos variáveis.

Palavras-chave: Acusativo anafórico de terceira pessoa; Ensino de Gramática em Três Eixos; Variação linguística.

\section{Abstract:}

\section{The representation of the anaphoric third-person accusative in a school context: diagnosis and proposal}

This article presents a diagnostic analysis carried out on the resumption of the anaphoric accusative, in essays by students in the 6th and 9th years of elementary school in a municipal school in Rio de Janeiro. Anchored in Variationist Sociolinguistics (WEINREICH; LABOV; HERZOG, 2006 [1968]; LABOV, 2008 [1972]), the investigation stems from the assumption that

* Doutoranda em Letras Vernáculas (UFRJ), licenciada em Português-Literaturas (UERJ) e mestre pela UFRJ, após ter sido docente da rede municipal de 2013 a 2017, atua desde então como professora efetiva da disciplina de Português, em turmas do ensino fundamental do Colégio Pedro II - Campus Realengo II. Lattes: http://lattes.cnpq.br/8712699246790475.E-mail: moniquelima@letras.ufrj.br. 


\begin{abstract}
language is variable and there are, therefore, different forms with the same representational value to express the accusative anaphoric third person. Based on the diagnostic analysis carried out, a didactic material was proposed for students from the 9th onwards, which could lend themselves to the teaching of pronouns - among which are the strategies for resuming the anaphoric accusative of the third person - in the school context. For the elaboration of the didactic material, it was based on the proposal of Teaching Grammar in Three Axes of VIEIRA (2017). The investigation now developed seeks to contribute both to the reflections on the teaching of the Portuguese language and to effective proposals for teaching variable phenomena.
\end{abstract}

Keywords: Anaphoric accusative of third person; Teaching of Grammar in Three Axes; Linguistic variation.

\section{Introdução}

No campo dos estudos da linguagem, a Sociolinguística é uma das áreas que estudam a relação entre língua e sociedade. A teoria e o método propostos pela Sociolinguística Variacionista (cf. WEINREICH; LABOV; HERZOG, 2006 [1968]; LABOV, 2008 [1972]) foram fundamentais para a descrição do comportamento de diversos fenômenos linguísticos do Português Brasileiro (PB), como já realizado por estudos anteriores. Tais investigações contribuíram para o mapeamento do PB em duas linhas: a da descrição, como se pode observar na obra Mapeamento sociolinguístico do português brasileiro, organizada por Martins e Abraçado (2015); e a do ensino - bem representada na obra Ensino de português e sociolinguística, organizada por Martins, Vieira e Tavares (2014).

A presente investigação insere-se nos estudos sociolinguísticos e é composta por uma parte descritiva e outra de reflexão sobre o ensino. Relata-se aqui uma pesquisa de mestrado, cujos objetivos iniciais eram de natureza: (i) diagnóstica: descrever o quadro pronominal utilizado por alunos matriculados no 6을 e no 9o anos do Ensino Fundamental de uma escola pública do Rio de Janeiro; e (ii) propositiva: elaborar um material didático que levasse em considera- ção a variação linguística presente no quadro pronominal do PB. Para o presente artigo, limitou-se à explanação da investigação desenvolvida sobre o acusativo anafórico de terceira pessoa, dentre as demais funções analisadas na pesquisa.

Para guiar a leitura desse texto, anuncia-se sua organização: após a introdução, apresentam-se os pressupostos teóricos da investigação empreendida (Seção 2); descreve-se brevemente o comportamento do acusativo anafórico de terceira pessoa nas modalidades oral e escrita do PB (Seção 3); relatam-se os aspectos teórico-metodológicos variacionistas adotados para a análise (Seção 4); reportam-se os resultados obtidos na pesquisa realizada (Seção 5); expõese parte do estudo dirigido desenvolvido para ensino das variantes do fenômeno em análise (Seção 6); tecem-se as considerações finais.

\section{Que contribuições a Sociolinguística trouxe para o campo do ensino de Língua Portuguesa?}

Uma das muitas contribuições da Sociolinguística Variacionista (WEINREINCH; HER- 
ZOG; LABOV, 2006 [1968]; LABOV, 2008 [1972]), corrente teórica em cujas bases se ancora esta investigação, diz respeito à constatação de que a variação contida na língua não leva ao caos da estrutura, isto é, a heterogeneidade linguística é sistematicamente ordenada. Apesar de o sistema linguístico ser heterogêneo - no qual duas formas de mesmo valor referencial podem ocorrer no mesmo contexto -, essa heterogeneidade possui regras. 0 sistema linguístico é capaz de comportar, ao mesmo tempo, regras categóricas (com só uma forma ocorrendo) e variáveis (com mais de uma forma).

No conjunto de fenômenos da língua, uma mudança em determinada estrutura é capaz de desencadear outra. Isso constitui um dos problemas empíricos propostos por Weinreich, Herzog, Labov (2006 [1968]): o do encaixamento. Esse problema discute a possibilidade novas mudanças serem associadas a uma certa mudança que ocorreu de maneira natural na língua. Para Tarallo (2018 [1993], p. 59), "as mudanças acontecem em teias e ecoam umas nas outras". Ainda nas palavras do professor Tarallo, em texto clássico, "cada mudança cria condições sociolinguísticas corretas e necessárias para que as outras se efetivem" (cf. TARALLO, 2018 [1993], p. 79).

No sistema pronominal do PB, observam-se indícios de mudança encaixada. A entrada do pronome "você" no quadro pronominal do PB - com valor referencial de segunda pessoa, em competição com a forma "tu" - por exemplo, parece ter sido ponto de partida para uma mudança no paradigma flexional dos verbos: perdeu-se, em quase todas as regiões, a flexão de segunda pessoa. Por sua vez, essa morfologia, entre outras funções, possibilitava também a recuperação da referência do sujeito, no caso dos sujeitos nulos do PB. Dessa maneira, a entrada do pronome "você" pode ser associada à mudança do paradigma flexional verbal, o que afetou também a expressão do sujeito no PB. Estudos sobre o sujeito no PB mostram que o $P B$ dá preferência a sujeitos pronominais expressos, a fim de preservar a referência, que não pode ser mais recuperada somente pela flexão verbal (cf. DUARTE, 2018 [1993]; entre outros).

Ainda dentro das mudanças relativas ao quadro pronominal, observa-se um movimento oposto quando se comparam os índices de preenchimento do sujeito e de apagamento do objeto anafórico de terceira pessoa. A esse respeito, Tarallo (2018 [1993], p. 79) observa o seguinte: "quando as percentagens para objetos diretos e sintagmas preposicionais diminuem, aumenta a proporção de retenção pronominal nos sujeitos, sugerindo que a perda da referência faz com que o sistema se rearranje [...].”.

Outro problema proposto no texto de inauguração da teoria sociolinguística diz respeito à avaliação, ou seja, como as formas variantes são avaliadas e qual o efeito dessa avaliação sobre a estrutura linguística. Em outras palavras, a força da avaliação social pode retardar ou acelerar um processo de mudança. Na visão de Labov (2008 [1972]), as variantes constitutivas de cada fenômeno linguístico assumem estatutos diferentes na fala e na escrita, podendo ser consideradas estereótipos - formas sobre as quais incide avaliação negativa -, marcadores - formas usadas de acordo com o grau de consciência e de disponibilidade no sistema linguístico do falante, e indicadores - formas comuns a todos falantes, sobre as quais não incide avaliação.

De maneira geral, tanto o problema do encaixamento quanto o da avaliação são interessantes ao ensino de língua materna. As formas linguísticas trabalhadas em sala de 
aula devem considerar as mudanças ocorridas na língua e o efeito da avaliação social sobre as formas variantes utilizadas, em registros mais ou menos monitorados, tanto da modalidade oral quanto da escrita, considerando os gêneros textuais através dos quais ocorre a comunicação.

A observação de que a variação, condicionada por fatores internos e externos à língua, é inerente a qualquer sistema linguístico e é sistematicamente ordenada, proporcionou um novo olhar científico para aquilo que era considerado "erro linguístico". No caso do PB, investigações de cunho variacionista realizadas desde a década de 70, iniciadas sob a orientação do professor Anthony Naro, colaboraram para a legitimação dessas estruturas entendidas anteriormente como "erro".

No contexto escolar, usos distintos daqueles predicados pelas gramáticas ou manuais didáticos utilizados para apoiar o ensino de Língua Portuguesa são conhecidos como "erros de gramática". Esses "erros" são apontados como desvio à norma-padrão - uma codificação abstrata que serve de referência em sociedades marcadas pela dialetação (cf. FARACO, 2008, p. 75). Tais "erros" recebem outros sinônimos, como "inadequação" ou "informalidade".

0 uso desses vocábulos mostra, em alguma medida, certo avanço proporcionado pelo olhar científico que a Sociolinguística trouxe sobre a variação. Há uma clara intenção, por parte dos elaboradores de materiais didáticos, de inserir a questão da variação linguística nos materiais, a fim de atender às orientações dos documentos oficiais, os Parâmetros Curriculares Nacionais (PCNs) e a Base Nacional Comum Curricular (BNCC), este último atualmente em vigor.

Lima (2014) constata que, para cumprir a exigência de incluir a variação linguís- tica em seu conteúdo, os livros tratam-na de maneira superficial, ao elencar, em um capítulo isolado do livro, os tipos de variação (diatópica, diafásica etc.), uma alusão às variações de natureza externa à língua. Os alunos são conduzidos, dessa maneira, a discussões rasas sobre a classificação da variação - cujos tipos não são independentes na dimensão interna da variação como descritos - e sobre preconceito linguístico. Não se reflete com o aluno acerca das variações de natureza interna à língua, nos níveis lexical, fonológico, morfossintático e discursivo, nos capítulos referentes ao estudo da estrutura linguística. Essa análise, sim, é imprescindível para trabalhar no ambiente escolar com a variação que efetivamente ocorre em distintos fenômenos do Português Brasileiro.

Não é possível discutir aqui as muitas lacunas encontradas nos manuais didáticos no ensino da variação linguística, mas cumpre destacar que tanto esse tratamento raso quanto a associação entre "erro" e "informalidade" são abordagens equivocadas, no sentido de que não promovem reflexão linguística efetiva nem contribuem para a produção ou recepção de formas linguísticas variantes. Especificamente em relação à (in) formalidade, os estudos da área já mostram que essa é uma característica associada à situação comunicativa em si, dependendo do tópico da situação comunicativa, relação com o interlocutor, entre outros fatores (cf. BORTONI-RICARDO, 2004, 2005; DUARTE; SERRA, 2015; entre outros).

Como trabalhar gramática na escola, privilegiando a relação entre forma, sentido e variação? Vieira (2017a) propõe três eixos para que seja trabalhado o ensino de gramática no contexto escolar. Para a autora, três objetivos gerais são interessantes ao ensino do componente gramatical: 
(i) promover o conhecimento teórico-descritivo sobre os recursos gramaticais; (ii) relacionar esses recursos ao vasto campo da produção de sentidos; e (iii) contemplar as expressões variáveis dos expedientes gramaticais. (VIEIRA, 2017b, p. 11)

Esses objetivos são diretamente relacionados aos três eixos de ensino propostos pela autora. Segundo Vieira (2017a), o Eixo I (Gramática e atividade reflexiva) trata dos conhecimentos linguísticos, isto é, dos elementos e conceitos que devem ser dominados pelos alunos; já o Eixo II (Gramática e produção de sentidos) observa a relação entre o componente gramatical e a produção de sentidos no nível textual; por fim, interessa ao Eixo III (Gramática e normas/variedades) a relação entre ensino de gramática e o domínio de normas considerando a realidade linguística do aluno. A concepção do ensino de gramática a partir desses eixos não pressupõe que sejam partes independentes entre si, isto é, não são eixos estanques, com fronteiras rígidas entre si. Pelo contrário, podem ser trabalhados em conjunto, embora haja especificidades de cada eixo.

Vieira (2017a) acredita que é um grande desafio conjugar (cf. VIEIRA, 2017a, p. 84) o ensino do componente gramatical à produção de sentidos, sem ser de forma rasa - limitada ao reconhecimento e classificação de formas -, e ainda trabalhar formas alternantes nos textos lidos ou produzidos. A partir da proposta da autora, alguns estudos - dissertações produzidas no âmbito do Mestrado Profissional em Letras - já se dedicaram à tarefa de produção de materiais didáticos que efetivamente coloquem em prática o ensino de gramática a partir dos três eixos (cf., entre outros, SOUZA, 2015; CHAGAS, 2016; GOUVÊA, 2016).

Para a elaboração do material didático desenvolvido para ensino de quadro prono- minal, a pesquisa ora relatada toma como base essa proposta de Vieira (2017a). Sabese do desafio que é trabalhar com a língua materna nas escolas, sem desprezar as diversas frentes de atuação, todas igualmente pertinentes. Atrelado ao trabalho com o componente gramatical e a produção de sentidos, o propósito desta investigação também é o de o promover o respeito ao conjunto de variedades em uso na fala e na escrita, evitando qualquer estigmatização de variantes linguísticas.

\section{A retomada anafórica do acusativo de terceira pessoa nas modalidades oral e escrita do PB}

O objeto direto anafórico de terceira pessoa pode ser representado por quatro formas específicas no Português Brasileiro: (a) o clítico acusativo ("Havia uma menina que possuía um espelho mágico. Só que um dia ela o quebrou sem querer."); (b) o pronome lexical ("Havia uma menina que possuía um espelho mágico. Só que um dia ela quebrou ele sem querer."); (c) o sintagma nominal ou SN anafórico ("Havia uma menina que possuía um espelho mágico. Só que um dia ela quebrou o espelho mágico sem querer."); e (d) o objeto nulo ("Havia uma menina que possuía um espelho mágico. Só que um dia ela quebrou [ø] sem querer.").

Os estudos mostram que essas formas variam de acordo com a modalidade linguística adotada (oral ou falada) assim como com o gênero textual em que essas formas aparecem. No Quadro 1, são apresentadas algumas características desse fenômeno a partir de pesquisas desenvolvidas sobre o tema. Cumpre, informar, porém que essa apresentação é breve e não se esgota nas próximas linhas. 
Quadro 1 - 0 acusativo anafórico de terceira pessoa nas modalidades oral e escrita do PB

O R A L I D A D E

$\rightarrow$ No PB atual, há ampla preferência pelo objeto nulo, o que foi licenciado após a perda de clíticos acusativos que começou a ocorrer no PB a partir do século XIX (cf. CYRINO, 1994). Essa variante é preferida mesmo na fala de indivíduos com baixa escolaridade (cf. OMENA, 1978).

$\rightarrow 0$ PB falado apresenta baixíssimos índices da variante de prestígio, clítico acusativo, mesmo no mais alto nível de escolaridade - esse uso fica restrito a determinados contextos linguísticos (cf. DUARTE, 1986; CORRÊA, 1991; AVERBUG, 1998).

$\rightarrow$ Na fala dos indivíduos com maior nível de escolaridade, há menor ocorrência da variante supostamente estigmatizada, pronome lexical (cf. DUARTE, 1986; CORRÊA, 1991; AVERBUG, 1998).

\section{E S C R I T A}

$\rightarrow$ A recuperação da variante clítico acusativo é feita via processo de escolarização, sendo o aumento dos índices dessa variante proporcional à subida do nível de escolaridade (cf. AVERBUG, 2000; FREIRE; 2005).

$\rightarrow$ A variante estigmatizada, pronome lexical, diminui com o aumento do grau de escolaridade, o que indica que o processo de letramento interfere também nessa variante (cf. AVERBUG, 2000; MACHADO, 2006).

$\rightarrow 0$ objeto nulo, variante preferida dos brasileiros na fala, encontra espaço na escrita do Português Brasileiro, nos três pontos do continuum (cf. FREIRE, 2005).

$\rightarrow$ No extremo de [+letramento] do continuum de oralidade-letramento (cf. FREIRE, 2005), o clítico acusativo é a forma mais utilizada. Nesse ponto, não há ocorrência de pronome lexical. Já no extremo [+oralidade], o clítico é a variante menos utilizada.

Fonte: elaborado pela autora.

$\mathrm{Na}$ pesquisa ora descrita, por se tratar de uma investigação sobre a escrita escolar - isto é, em processo de letramento -, observar o comportamento do acusativo anafórico tanto na fala quanto na escrita é importante, uma vez que os dados de escrita observados recebem influência da fala. Assim, justifica-se a revisão do fenômeno nas duas modalidades da língua.

\section{Metodologia de composição do corpus de redações escolares e de análise variacionista}

Na investigação em questão, a análise sobre os usos pronominais recorrentes na escrita dos estudantes foi realizada com base em um corpus de redações escolares, que serviam de avaliação bimestral - a prova de "produção textual". Dessa maneira, não foi possível interferir no comando de elaboração dos textos, que era previamente elaborado pela Secretaria Municipal de Educação (SME-RJ). O corpus foi composto por 201 redações: 85 produzidas pelo 6음 ano e 116 pelo 9․ Essas redações foram desenvolvidas pelos alunos no $1^{\circ}$ e no $4^{\circ}$ bimestres, isto é, na primeira e na última avaliação de produção textual. O Quadro 2, a seguir, reproduz as propostas motivadoras para a elaboração dos textos. 
Quadro 2 - As propostas motivadoras para a produção das redações

TEMA: Escolha um personagem de um dos livros que leu neste bimestre e escreva uma nova história em que ele será o personagem principal. Essa nova

1 o bimestre $/ 6^{\circ}$ história acontecerá em um outro espaço, um mundo mágico em que tudo é possível. Conte como a história começa, o que acontece com o personagem e como a história termina.

TEMA: Escreva um pequeno conto em que o protagonista seja um dos perso-

1 o bimestre/9o nagens de um livro que você leu neste bimestre. Lembre-se da estrutura do conto: situação inicial, conflito gerador, clímax e desfecho.

TEMA: Escolha uma história que você tenha lido neste bimestre e de que tenha gostado. Escreva a continuidade da história, contando o que aconteceu

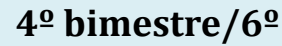
após o seu desfecho. Nessa nova história, você pode levar os personagens para um outro tempo e para um espaço diferente. Além disso, pode incluir novos personagens. Lembre-se de que o seu texto deve apresentar situação inicial, complicação - do conflito gerador ao clímax - e desfecho.

4음 bimestre/9o

TEMA: Escreva uma crônica narrativa a partir de uma situação apresentada em um dos livros lidos por você neste bimestre. Lembre-se da estrutura dos textos de base narrativa e das características de uma crônica.

Fonte: adaptação de LIMA, 2017, p. 66-67.

Nos textos elaborados pelos alunos, houve predomínio do modo narrativo de organização do discurso. Um dos objetivos dos Cadernos Pedagógicos - material didático utilizado no âmbito da SME-RJ - é trabalhar a estrutura dos gêneros textuais, o que também inclui os modos de organização do discurso. Nas propostas em questão, percebe-se uma preocupação da Secretaria em relação à estrutura do modo narrativo de organização do discurso; havia uma orientação explícita para que os alunos colocassem em prática a ordem canônica da narrativa, ou seja, situação inicial, conflito gerador, clímax e desfecho: "Lembre-se de que o seu texto deve apresentar situação inicial, complicação - do conflito gerador ao clímax - e desfecho".

Quanto à temática, nas propostas havia a orientação de que os textos deveriam ser baseados em livros que os alunos supostamente teriam lido naquele bimestre letivo. Entretanto, por se tratar de leitura livre, muitos alunos - inclusive os de $9^{\circ}$ ano - basearam suas produções textuais em contos clássicos conhecidos, como Chapeuzinho
Vermelho, Os Três Porquinhos, Branca de Neve e outros do mesmo gênero, ou mesmo em filmes de grande apelo popular, como Batman, Os Vingadores, Velozes e Furiosos e A culpa é das estrelas.

Como as propostas exigiam a predominância do modo narrativo de organização do discurso em $3^{\text {a }}$ pessoa, acreditou-se que haveria mais ocorrências de acusativo dessa pessoa do que as demais funções das outras pessoas pronominais, o que foi confirmado na coleta dos dados. Para essa função, o tratamento dos dados foi realizado no programa Goldvarb-X, ferramenta utilizada para obtenção de frequências, proporções e pesos relativos. Assim, seguiram-se os seguintes passos: coleta de dados; codificação de acordo com as variantes pré-estabelecidas; realização de rodadas no programa estatístico; e interpretação, qualitativa e quantitativa, dos resultados.

\section{Análise e discussão dos resultados obtidos}

Com já havia se cogitado, foram encontradas 373 ocorrências de acusativo anafórico 
de terceira pessoa, mais do que o dobro dos 127 dados referentes às demais pessoas e funções estudadas na investigação. Desse total, foram retirados 15 dados de antecedente oracional, restando 358 ocorrências para análise. Os dados retirados retomavam orações por meio das seguintes estratégias: objeto nulo, SN anafórico e clítico acusativo. Os exemplos a seguir ilustram cada uma dessas categorias:

(1) "ela mandou matar-la. A Branca de neve descobriu [Ø] e fugiu” (Redação
067, turma $1901,1^{\circ}$ bimestre)

(2) "digo a mim mesma que todos iremos cair um dia, somos programados a fazê-lo" (Redação 096, turma 1901, $1^{\circ}$ bimestre)

(3) "Hussi foi para o seu quarto e pegou seus brinquedos, roupas, enquanto seus amigos faziam o mesmo e ele disse" (Redação 091, turma 1901, $1^{\circ}$ bimestre)

A Tabela 1, a seguir, exemplifica os resultados obtidos na análise realizada:

Tabela 1 - Distribuição geral das ocorrências de acusativo anafórico de terceira pessoa no corpus de redações escolares de $6^{\circ}$ e 90 anos de ensino fundamental

\begin{tabular}{|l|c|c|}
\multicolumn{1}{|c|}{$\begin{array}{c}\text { Estratégia de representação do } \\
\text { acusativo anafórico de 3a pessoa }\end{array}$} & Valor absoluto & Valor percentual \\
\hline SN anafórico & $180 / 358$ & $50,3 \%$ \\
\hline Pronome clítico & $77 / 358$ & $21,5 \%$ \\
\hline Pronome lexical & $65 / 358$ & $18,1 \%$ \\
\hline Objeto nulo & $36 / 358$ & $10,1 \%$ \\
\hline
\end{tabular}

Fonte: LIMA, 2017, p. 90.

A seguir, ilustram-se as quatro variantes utilizadas pelos alunos para a expressão do acusativo anafórico de terceira pessoa:

(4) SN anafórico: "A idosa ${ }_{i}$ estava no celular... Eles não denunciaram $\boldsymbol{a}$ idosa" (Redação 146, turma 1901, $4^{\circ}$ bimestre)

(4) Clítico acusativo: "Mas um belo dia eles viram pessoas saindo da cidade mágica, e $\boldsymbol{a} \boldsymbol{s}_{\mathrm{i}}$ seguiram" (Redação 006, turma $1603,1^{\circ}$ bimestre)

(4) Pronome lexical: "A entidade viu que Wander tinha a espada $a_{\mathrm{i}}$ sagrada e ficou surpreso possuir ela $_{\mathrm{i}}$ " (Redação 087, turma $1901,1^{\circ}$ bimestre)

(4) Objeto nulo: "me dá a cesta ${ }_{\mathrm{i}}$.. eu não vou da $[\emptyset]_{i}$ porque a vovó vai ficar sem" (Redação 062, turma 1603, $4^{\circ}$ bimestre)
Os resultados da Tabela 1 evidenciam a alta ocorrência de SN anafóricos (50,3\%), forma considerada neutra na retomada do acusativo anafórico de terceira pessoa. Em segundo lugar, aparece o clítico acusativo (21,5\%), forma considerada como padrão. No terceiro lugar, aparece o pronome lexical $(18,1 \%)$, forma sobre a qual recai estigma na avaliação social do fenômeno. Por fim, aparece o objeto nulo $(10,1 \%)$.

Como referido pela literatura, o SN anafórico e o objeto nulo são as estratégias mais neutras com relação à percepção dos falantes, sendo consideradas estratégias de "esquiva" ao uso do pronome clítico - pouco familiar aos brasileiros - e ao pronome lexical - mais estigmatizado (cf. DUARTE, 2013; entre outros).

Uma vez que o corpus analisado trata de redações escolares - ou seja, uma escrita em 
fase de letramento e que não seria de grau máximo de monitoração -, pode ser que essas estratégias de esquiva não sejam plenamente dominadas pelos alunos. Em função disso, na análise, foram realizadas duas rodadas multivariadas com base nos outros dois valores de aplicação: (a) o clítico acusativo e (b) o pronome lexical, que são as variantes menos neutras. Os resultados de cada análise serão explorados a seguir.

\section{- Variáveis relevantes ao emprego do clítico acusativo}

Quanto ao emprego do clítico acusativo, o programa selecionou três variáveis relevantes ao uso desta variante - duas linguísticas e uma extralinguística: a distância entre o termo antecedente e o acusativo anafórico (1 $\left.{ }^{\mathrm{a}}\right)$; a animacidade do antecedente ( $3^{\mathrm{a}}$ ); e o ano escolar $\left(2^{\underline{a}}\right)$.

Tabela 2 - Atuação da variável "distância entre o antecedente e o acusativo anafórico" quanto ao emprego do clítico.

\begin{tabular}{c|c|c|c}
\hline $\begin{array}{c}\text { Distância entre o antecedente e } \\
\text { o acusativo anafórico }\end{array}$ & Valor absoluto & Valor percentual & Peso relativo \\
\hline Perto & $74 / 283$ & $26,1 \%$ & .61 \\
\hline Longe & $3 / 75$ & $4 \%$ & .14 \\
\hline Total & $77 / 358$ & $21,5 \%$ & \\
\hline
\end{tabular}

Fonte: LIMA, 2017, p. 93.

Como se pode observar pela Tabela 2, no corpus de redações escolares, a retomada anafórica por pronomes clíticos foi favorecida pelo fato de o antecedente se encontrar perto do acusativo anafórico (.61). Por outro lado, quando o antecedente do acusativo anafórico se encontrava em uma distância estrutural de cinco orações, a retomada por pronome clítico foi desfavorecida (.14).

Esses resultados confirmam a hipótese de Xavier (2015) de que o pronome clítico dificilmente apareceria no caso de retomada de um antecedente distante estruturalmente - contexto linguístico favorecedor da retomada por $\mathrm{SN}$ anafórico. $\mathrm{Na}$ análise, isso se confirma também na apreciação dos resultados gerais, em que houve mais aparecimento de SNs anafóricos em contexto [+ distante], 74,7\% das ocorrências, do que na junção das demais variantes $(25,3 \%)$. Esses dados corroboram a literatura quanto à suposição de que - em caso de antecedentes estruturalmente distantes - a retomada pelo SN facilitaria a referência ao antecedente, evitando qualquer ambiguidade.

Em relação à variante $\mathrm{SN}$ anafórico - especificamente nos casos em que o antecedente se encontrava mais distante -, cabe mencionar que houve mais ocorrências de SNs idênticos e semelhantes - respectivamente $23(30,7 \%)$ e $22(29,3 \%)$ - do que de SNs sinônimos, num total de $11(14,7 \%)$, conforme ilustrado na Tabela 3 , a seguir.

Tabela 3 - Distribuição das ocorrências da variante sintagma nominal com antecedente [+ distante]. Acusativo anafórico de 3 a pessoa

\begin{tabular}{c|c|c|c|c|c}
\multicolumn{2}{c|}{ SN idêntico } & \multicolumn{2}{|c|}{ SN semelhante } & \multicolumn{2}{c}{ SN sinônimo } \\
\hline $23 / 76$ & $30,7 \%$ & $\mathbf{2 2} / 67$ & $29,3 \%$ & $\mathbf{1 1} / 37$ & $14,7 \%$ \\
\hline
\end{tabular}

Fonte: LIMA, 2017, p. 93. 
Em Santana (2016), resultados semelhantes também foram encontrados. Na retomada por SN anafórico, parece haver preferência por manter o núcleo do antecedente, a fim de preservar a referência dentro do texto.

Os estudos sobre o fenômeno de retomada do acusativo de terceira pessoa apontam que a incidência de clítico acusativo aumenta conforme sobe o nível de escolaridade do falante (cf. AVERBUG, 2000; FREIRE, 2005; entre outros), isto é, há uma atuação forte desse fator no emprego do clítico. $\mathrm{Na}$ análise das redações escolares, ano escolar (ou nível de escolaridade) foi o segundo grupo de fatores que atuou no favorecimento do pronome clítico para a retomada do referente de terceira pessoa. No corpus analisado, houve mais favorecimento do clítico acusativo entre os alunos de $9^{\circ}$ ano - com peso relativo de .62 - do que entre os alunos dos $6^{\circ}$ ano (.31), como mostra a Tabela 4 .

Tabela 4 - Atuação da variável "ano escolar" quanto ao emprego do clítico.

\begin{tabular}{c|c|c|c}
\hline Ano escolar & Valor absoluto & Valor percentual & Peso relativo \\
\hline $6^{\circ}$ & $14 / 139$ & $10,1 \%$ & .31 \\
\hline $9^{\circ}$ & $63 / 219$ & $28,8 \%$ & .62 \\
\hline Total & $77 / 358$ & $21,5 \%$ & \\
\hline
\end{tabular}

Fonte: LIMA, 2017, p. 94.

Esses resultados corroboram os anteriores ao confirmar que o uso do clítico acusativo - diferentemente do que ocorre na fala - é fortemente relacionado ao processo de escolarização, no que se refere ao aumento das experiências de letramento. Cabe ressaltar que o recorte do corpus analisado na investigação representa a escrita em processo de letramento, em que se percebem diversos desvios da ortografia padrão, decorrentes da interferência da fala. A leitura das redações escolares do $6^{\circ}$ ano, por exemplo, permitiu verificar diversas influências da fala na escrita ou ao menos pouca familiaridade com a modalidade escrita, como evidencia o exemplo a seguir.

(8) "e a moça falou sera que essa pata choga ovo e ela penso que era mulher... e gocou a pata fora"1 $^{1}$ (Redação 044, turma1604, $1^{\circ}$ bimestre)

Nas palavras "choga" e "gocou", percebe-se no uso dos fonemas /k/ e /g/, a falta

1 "E a moça falou: - será que essa pata choca ovo? E ela pensou que era mulher... E jogou a pata fora." de percepção da distinção fonológica entre eles, o que evidencia que o processo de letramento ainda não conseguiu solucionar esse tipo de desconhecimento. Além disso, ainda na grafia de "gocou", há uma questão de ordem ortográfica, que é o uso das letras "g" e "j" para grafar o fonema /3/: como "geada" é grafada com "g", no raciocínio do aluno, "jogou" também seria. Outra convenção da escrita desconhecida para esse estudante, evidenciada nesse trecho, é referente à pontuação. A inserção de discurso direto sem a utilização de recursos gráficos, tais quais travessão ou aspas, certamente é um indicador da pouca familiaridade desse aluno com as convenções da escrita.

Por sua vez, nas redações do $9^{\circ}$ ano, também se evidenciam indicadores de que essa é uma escrita em construção. De fato, pode-se perceber um aumento no uso de pronomes clíticos em função acusativa no último ano do ensino fundamental; entretanto, o uso dessa estratégia de retomada ainda não é plenamente dominado pelos alunos desse ano es- 
colar. No Exemplo 9, a seguir, isso pode ser observado. Embora o antecedente tenha sido retomado com um pronome clítico, variante apresentada pela escola, esse apresenta marcas de plural, apesar de retomar um termo usado no singular ("cinderela").

(9) "tinha duas filhas que não gostava da cinderela. As filhas da sua madrasta $\boldsymbol{a s}_{\mathrm{i}}$ detestava" (Redação 131, turma 1902, 1º bimestre).
Diante desse exemplo, há um indício de que, apesar de a escola conseguir introduzir a variante padrão (clítico acusativo), mesmo nos anos finais do ensino fundamental, o aluno ainda não tem pleno domínio dessa forma de prestígio (cf. FREIRE, 2005).

0 gráfico a seguir revela a distribuição geral dos dados, levando em consideração os dois anos de escolares envolvidos.

Gráfico 1 - Distribuição (\%) das variantes para expressão o objeto direto de $3^{\text {a }}$ pessoa entre o $6^{\circ}$ e o $9^{\circ}$ anos do Ensino Fundamental.

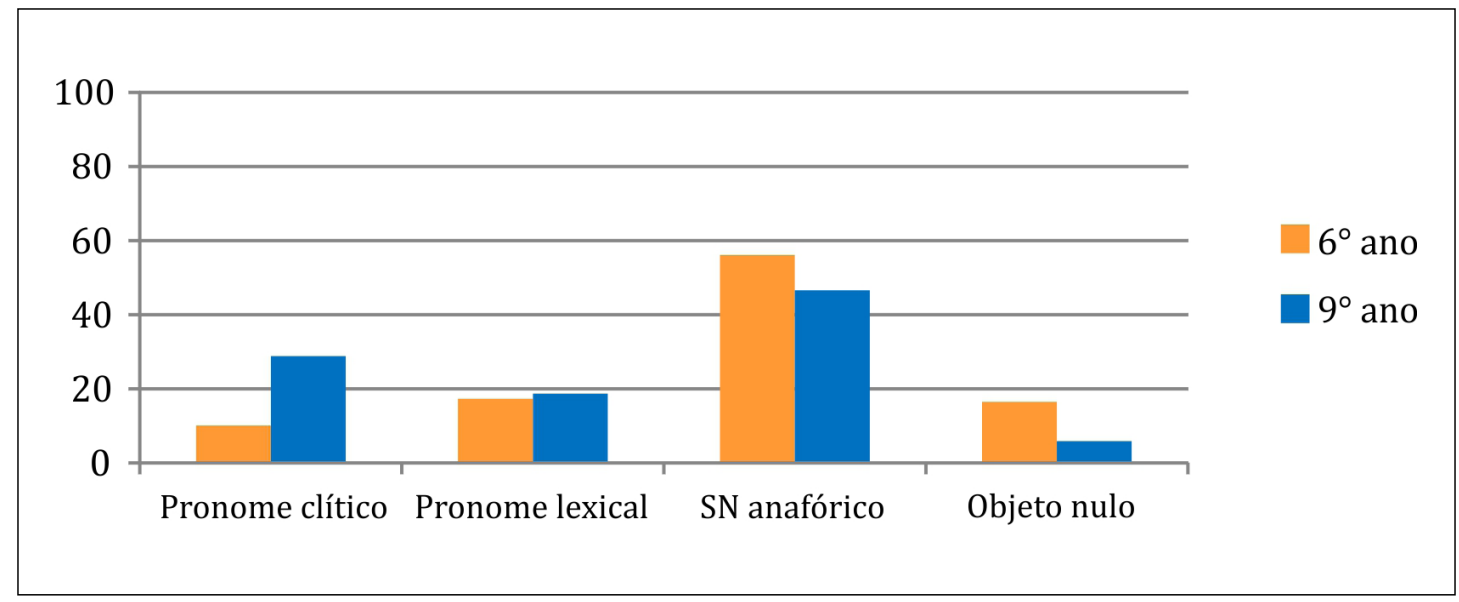

Fonte: LIMA, 2017, p. 95.

Pelo disposto no gráfico, torna-se perceptível o aumento do uso da variante padrão - pronome clítico - no ano final do ensino fundamental, o que era esperado com base nas pesquisas anteriores. Ainda em relação à mesma variante, o gráfico revela menor produtividade dessa variante, e natural aumento das demais, nas redações dos alunos do $6^{\circ}$ ano.

0 último grupo de fatores selecionado na análise estatística foi a animacidade do antecedente. Assim como em pesquisas anteriores, o traço [+ animado] se mostrou relevante para as ocorrências da forma de prestígio. 0 uso do pronome clítico foi favorecido quando o antecedente possuía o traço [+ animado] - com peso relativo de .57 - e o uso dessa estratégia de retomada foi desfavorecido em contextos de antecedente [-animado] - peso relativo de 28 .

Tabela 5 - Atuação da variável "animacidade do antecedente” quanto ao emprego do pronome clítico.

\begin{tabular}{c|c|c|c}
\hline Animacidade do antecedente & Valor absoluto & Valor percentual & Peso relativo \\
\hline Animado & $71 / 273$ & $26 \%$ & .57 \\
\hline Inanimado & $6 / 85$ & $7,1 \%$ & .28 \\
\hline Total & $77 / 358$ & $21,5 \%$ & \\
\hline
\end{tabular}

Fonte: LIMA, 2017, p. 96. 
$\mathrm{Na}$ Tabela 5, os resultados dispostos mostram que o clítico acusativo ocorreu majoritariamente com referência a antecedentes [+ animados], correspondendo a $26 \%$ dos dados relativos ao mesmo contexto linguístico. Ao observar essa produção separadamente - pelo recurso do cruzamento de grupos de fatores (crosstabulation) -, percebe-se que, dos 14 dados de clítico acusativo produzidos pelo $6^{\circ}$ ano, 12 possuíam antecedente [+animado]. De modo semelhante, dos 63 clíticos produzidos pelo $9^{\circ}$ ano, 59 apresentavam antecedente [+ animado]. Isso confirma que, nos dois anos escolares, houve preferência pelo clítico acusativo com antecedente [+ animado].

\section{- Variáveis relevantes ao emprego do pronome lexical}

A melhor rodada selecionada pelo programa, com base na variante pronome lexical, apresentou nível de significância .04, com um input geral de aplicação de .13, um pouco menor do que o input do pronome clítico (.15). Essa baixa aplicação geral constitui indicadores de que essas variantes não são estratégias produtivas para a retomada do objeto direto, sendo o uso restrito a determinados contextos linguísticos.

O programa selecionou três variáveis - duas linguísticas e uma extralinguística como relevantes ao uso do pronome lexical, nesta ordem: animacidade do antecedente, estrutura sintática da frase e turno escolar. Esses fatores são descritos a seguir.

Indubitavelmente - como anunciado em pesquisas anteriores -, o fator animacidade do antecedente favorece a realização do pronome lexical em função acusativa. De modo semelhante, na presente pesquisa, também houve favorecimento do ele acusativo em contexto de antecedente com traço [+ animado] - com peso relativo de .63. Por outro lado, houve desfavorecimento dessa forma de retomada quando o antecedente possuía o traço [- animado].

Tabela 6 - Atuação da variável "animacidade do antecedente" quanto ao emprego do pronome lexical.

\begin{tabular}{|c|c|c|c|}
\hline Animacidade do antecedente & Valor absoluto & Valor percentual & Peso relativo \\
\hline Animado & $63 / 273$ & $23,1 \%$ & .63 \\
\hline Inanimado & $2 / 85$ & $2,4 \%$ & .15 \\
\hline Total & $65 / 358$ & $18,2 \%$ & \\
\hline
\end{tabular}

Fonte: LIMA, 2017, p. 97.

As pesquisas anteriores mostram que o "ele" acusativo é mais favorecido quando há o traço [+ animado] no antecedente (cf. OMENA, 1978; DUARTE, 1986; entre outros). Ainda pelo recurso de crosstabulation, foi possível observar que o pronome lexical foi amplamente favorecido com o antecedente animado, tanto no $6^{\circ}$ quanto no $9^{\circ}$ ano. Analisando individualmente o comportamento dos anos escolares envolvidos, foi possível verificar que todos os dados $(24 / 24)$ de pronome lexical - produzidos pelo $6^{\circ}$ ano - possuíam esse traço; assim como os 39 do total de 41 realizados pelo $9^{\circ}$ ano.

Vale lembrar que Averbug (2000) constatou que a inversão entre o uso do pronome clítico e do pronome lexical começa no $9^{\circ}$ ano: há um declínio do uso do pronome lexical e uma consequente subida no uso do pronome clítico. Observando separadamente, o $6^{\circ}$ ano produziu 14 dados de clíticos acusativos e 24 de pronomes lexicais. Já o $9^{\circ}$ ano produziu 63 dados de clíticos acusativos 
e 41 de pronomes lexicais. De fato, a análise do $9^{\circ}$ ano mostra que houve um aumento da produção de pronomes clíticos paralelamente à diminuição de pronomes lexicais, para a retomada do objeto anafórico.

Embora haja diferença no comportamento por série, fica claro, ao verificar os dados por meio do recurso de crosstabulation, que, dentre todas as variantes para retomada do acusativo, o uso da estratégia supostamente desprestigiada para contextos escritos formais se mantém de forma proporcional: o $6^{\circ}$ apresenta $17 \%$ de pronomes lexicais, e o $9^{\circ}$ ano, $19 \%$. Considerando que se trata de escrita escolar, acredita-se que o uso da variante pronome lexical ainda esteja bem presente nesses textos do fim do ensino fundamental, porque o processo de letramento ainda está incompleto, e a escola, embora tenha introduzido o clítico, ainda não conseguiu eliminar os usos da variante estigmatizada.

Em relação à estrutura projetada pelo predicador verbal, as ocorrências de objeto direto anafórico de $3^{\mathrm{a}}$ pessoa foram distribuídas conforme a Tabela 7 a seguir.

Tabela 7 - Atuação da variável estrutura sintática da frase quanto ao emprego do pronome lexical.

\begin{tabular}{c|c|c|c}
\hline Estrutura sintática da frase & Valor absoluto & Valor percentual & Peso relativo \\
\hline S V OD & $37 / 282$ & $13,1 \%$ & .44 \\
\hline SV OD Complementos & $19 / 52$ & $36,5 \%$ & .71 \\
\hline SV OD “miniorações" & $9 / 24$ & $37,5 \%$ & .69 \\
\hline Total & $65 / 358$ & $18,2 \%$ & \\
\hline
\end{tabular}

Fonte: LIMA, 2017, p. 98.

Os resultados confirmam as hipóteses formuladas, nas pesquisas anteriores, de que as construções de "dupla função" e as estruturas SV OD seguidas de outros complementos (OI ou Oblíquo) favorecem o uso do pronome lexical: pesos relativos de $.69 \mathrm{e}$ .71 , respectivamente.

Também nessas estruturas complexas, nas quais o termo acusativo exerce "dupla função" - ilustradas em (10), (11) e (12) a seguir -, não houve ocorrência de objeto nulo. Isso estaria diretamente relacionado com o preenchimento do sujeito (cf. DUARTE, 2018 [1993]; entre outros): se o termo acusativo também funciona como sujeito, logo aparece preenchido (por SN, pronome clítico ou pronome lexical), não referendando a ocorrência da variante zero nesse contexto linguístico. A título de exemplificação, em (12), o pronome lexical "ele" funciona como sujeito do verbo ir e faz parte da oração selecionada como objeto direto do verbo deixar.

(10) "não sabia que ela sempre ia no mercado para roubar (...) Chegando no mercado entramos na sessão de bebidas alcoolicas e eu vi ela colocando uma garrafa de vinho dentro de uma bolsa" (Redação 129, turma $1902,1^{\circ}$ bimestre)

(11) "pelo udimo foi um pato muito feio (...) e os soutros pato ficou chamando ele de feio" (Redação 044, turma 1604, $1^{\circ}$ bimestre)

(12) "mais ela não deixou, depois ela mudou e deixou ele ir" (Redação 065, turma $1603,4^{\circ}$ bimestre)

Mais uma vez, esses exemplos também evidenciam uma escrita com interferências da oralidade ou sem pleno domínio das convenções ortográficas, principalmente entre os alunos de 6ํㅜ ano do ensino 
fundamental. No Exemplo (11), observa-se o uso de "udimo" em vez de "último", em que se percebe a falta de distinção entre os fonemas /t/ e /d/, além da perda da lateral. Destaca-se ainda a grafia de "outros" como "soutros", um uso comum, quando o estudante traz a divisão silábica fonológica para a escrita.

A criação da última variável selecionada como relevante, turno escolar, buscava veri- ficar a hipótese de que os alunos da manhã teriam um comportamento linguístico diferente do dos alunos da tarde, quanto ao uso do pronome lexical: supunha-se que haveria mais produção de pronomes lexicais no grupo de alunos da tarde, pois eles eram mais velhos e já haviam repetido o ano escolar. A Tabela 8 apresenta o comportamento dessa variante linguística de acordo com o grupo de fatores turno escolar.

Tabela 8 - Atuação da variável "turno escolar" quanto ao emprego do pronome lexical.

\begin{tabular}{c|c|c|c}
\hline Turno escolar & Valor absoluto & Valor percentual & Peso relativo \\
\hline Manhã & $45 / 207$ & $21,7 \%$ & .56 \\
\hline Tarde & $20 / 151$ & $13,2 \%$ & .41 \\
\hline Total & $65 / 358$ & $18,2 \%$ & \\
\hline
\end{tabular}

Fonte: LIMA, 2017, p. 99.

A tabela, entretanto, revela justamente o contrário: aparentemente, os alunos da manhã (.56) favoreceram mais o uso do pronome lexical do que os alunos da tarde (.41). A diferença não parece expressiva, apesar de o programa ter selecionado essa variável como relevante. Novamente, o recurso de crosstabulation permitiu que se analisasse individualmente cada ano escolar, dividido pelos turnos. $06^{\circ}$ ano da manhã produziu 18 do total de 24 dados (75\%) relativos a esse ano escolar. Já a turma da tarde produziu 6/24 (25\%), no mesmo contexto. Em relação às turmas de $9^{\circ}$ ano, houve $27 / 41$ $(65,9 \%)$ nas turmas da manhã, e $14 / 41$ $(34,1 \%)$ nas turmas da tarde.

A hipótese inicial, porém, não foi confirmada. Entretanto, o comportamento claramente distinto entre os dois turnos escolares permite outra consideração. Os alunos da manhã - apesar da origem em escolas mais tradicionais - são mais novos do que os alunos da tarde - entre 1 ou 2 anos -; por outro lado, muitos alunos da tarde já repetiram o mesmo ano escolar. Provavel- mente, esses alunos da tarde - pela idade e pela repetição do mesmo ano escolar - se encontram em um estágio de apropriação da escrita letrada diferente dos alunos mais novos e cursando aquele ano escolar pela primeira vez. Para verificar se de fato isso ocorreu, seria necessário controlar novamente essa variável, associando-a especificamente à idade dos alunos e à repetição ou não de ano escolar.

Especificamente em relação ao acusativo anafórico de $3^{a}$ pessoa - função que apresentou maior frequência de ocorrências -, foi possível observar alguns condicionamentos para esses usos. Como era previsto, há maior frequência das formas neutras SNs $(50,3 \%)$ e objetos nulos $(10,1 \%)$ - no corpus analisado, chegando a um total de $60,4 \%$. Isso corrobora resultados de pesquisas anteriores, que encontraram mais ocorrências também dessas formas, conhecidas como estratégia de esquiva (cf. DUARTE, 2013).

Chama a atenção, como nas pesquisas anteriores - a influência da escolarização 
para o aumento gradativo de usos da variante-padrão (clítico acusativo). Ao comparar a frequência de usos dessa variante entre as turmas de $6^{\circ}$ e $9^{\circ}$ anos do ensino fundamental, a análise revelou que - entre os alunos deste último grupo - houve um aumento de ocorrências do clítico acusativo. 0 processo relativamente inverso disso ocorreu em relação ao uso do pronome lexical: os alunos do $9^{\circ}$ ano apresentaram menor frequência dessa variante. Ainda de acordo com pesquisas anteriores (cf. AVERBUG, 2000 SANTANA, 2016; entre outros), essa inversão é resultado do processo de escolarização e ocorre justamente nesse ano escolar.

Quanto à inversão dos usos de pronomes lexicais e clítico, cabe lembrar que os alunos do $9^{\circ}$ ano escolar têm uma bagagem de leitura mais ampla, em função até ao tempo de escolaridade, do que os alunos de $6^{\circ}$. 0 contato com livros diversos de literatura infanto-juvenil colabora para o aprendizado das variantes linguísticas preconizadas nesse gênero textual. As ocorrências do clítico acusativo foram encontradas, principalmente, nos textos dos alunos que basearam sua escrita em alguma obra lida no trimestre.

Isso se refletiu, por exemplo, na diferença dos textos escritos para o $1^{\circ}$ e para o $4^{\circ}$ bimestre, entre os alunos do 9o ano. Em ambos, os alunos deveriam escrever redações baseadas em obras lidas. Entretanto, no último bimestre - por uma orientação do professor do ano escolar-, os alunos foram incumbidos de elaborar uma notícia. Como eles não trabalhavam com produção de notícias desde o 7ํo ano, os textos ficaram bem próximos da narrativa de uma história. Nessa segunda produção textual - criada pelos alunos, sem a exigência de que fosse baseada em uma obra literária -, surpreendentemente, houve uma diminuição na frequência de uso da variante padrão. Esse detalhe in- dica que, provavelmente, a variante padrão pode ser mais utilizada pelos alunos, quando seu texto se refere a outro mais letrado (textos literários).

A seguir, apresenta-se parte da proposta pedagógica desenvolvida a partir da diagnose realizada acerca dos usos pronominais, em específico, das formas de retomada do acusativo anafórico de terceira pessoa.

\section{Uma proposta para trabalhar com a retomada do acusativo anafórico no contexto escolar}

A ideia de produzir uma unidade didática para ensino reflexivo da temática do quadro pronominal - foi motivada por duas razões específicas. A primeira é a constatação de que os materiais oferecidos aos alunos da rede municipal de ensino, tanto os livros quanto os cadernos pedagógicos oferecidos pela SME-RJ, não abordavam as formas pronominais de maneira completa (cf. SANTANA, 2016). A título de exemplo, formas inovadoras como "você" e "a gente" não são reconhecidas, em tais manuais, como pronomes legítimos do Português Brasileiro não obstante sua descrição em pesquisas científicas.

Já a segunda motivação está relacionada às preocupações gerais da pedagogia da variação linguística (cf. BORTONI-RICARDO, 2004, 2005; FARACO, 2008, 2015; VIEIRA, 2014, 2017a, 2017b; entre outros), quanto ao que deve ser ensinado nas aulas de Língua Portuguesa. Uma dessas preocupações é reforçada pelas considerações de Barbosa (2015) sobre a necessidade de criação, pela presente geração, de materiais que promovam a reflexão sobre as estruturas da língua, considerando os saberes que os alunos já apresentam sobre o vernáculo, os saberes descritos/prescritos pelas gramáticas nor- 
mativas assim como os saberes descritos pelas pesquisas linguísticas. Para o autor, só a partir da combinação desses saberes seria possível promover a reflexão linguística em contexto escolar. Barbosa (2015) ainda defende, nesse sentido, a necessidade de formar licenciandos em Letras conscientes dessa discussão, uma vez que eles, na sua grande maioria, atuarão nas salas de aula.

0 estudo dirigido elaborado foi dividido em seis módulos: cada um voltado para uma função específica dos pronomes, nos quais os usos pronominais eram abordados a partir da proposta de Ensino de Gramática em Três Eixos (cf. VIEIRA, 2017a). O quinto módulo é o que será descrito nessa seção, pois trata exclusivamente do acusativo anafórico de terceira pessoa. Nesse módulo, além de estudar as formas pronominais utilizadas para representar o acusativo anafórico $\mathrm{o}(\mathrm{s}) / \mathrm{a}(\mathrm{s})$ e seus alomorfes e ele(s)/ela(s) - são apresentadas aos alunos, de maneira sistemática, as outras duas formas descritas pelos estudos do fenômeno: os SN anafórico e o objeto nulo. 0 trabalho foi desenvolvido para turmas de 9o ano ensino médio em diante, pois esse grupo escolar teria um acúmulo maior de reflexão linguística e conhecimento metalinguístico para trabalhar com os pronomes de forma plena.

Antes de cada módulo, foi inserida uma caixinha com informações sobre aquela parte do material didático descrevendo os objetivos gerais e a relação das questões com os Três Eixos de Ensino de Vieira (2017a). 0 Quadro 3, a seguir, reproduz as informações referentes ao estudo do objeto anafórico de terceira pessoa.

Quadro 3 - 0 Módulo V: estudo da retomada do acusativo anafórico de terceira pessoa

Módulo V: Essa parte inicia o trabalho específico com os pronomes-objeto de $3^{\mathrm{a}}$ pessoa, observando o objeto direto anafórico. Na elaboração desse módulo, foram selecionados 4 textos e propostas 7 questões.

Objetivos: $O$ objetivo principal é promover o reconhecimento das variantes do acusativo anafórico - pronominais ou não - em seu contexto de uso, ou seja, nos contínuos de variação linguística. Como já indicado anteriormente, privilegia-se na presente pesquisa a abordagem dos contínuos de oralidade-letramento e monitoração estilistica.

Justificativa: Esse módulo justifica-se, uma vez que busca promover o reconhecimento do acusativo anafórico de $3^{\mathrm{a}}$ pessoa enquanto fenômeno variável. Para tanto, novamente, o Eixo III é abordado para fazer com que o aluno perceba a distribuição das variantes pronominais (padronizadas ou não) e também das variantes não pronominais. A partir da associação do Eixo III ao Eixo II, é possível observar em quais modalidades de texto e também/ em qual grau de monitoração estilistica são utilizadas as quatro variantes que expressam o objeto direto anafórico de $3^{\mathbf{a}}$ pessoa. Por fim, essa parte é realizada a partir do Eixo I, com as atividades linguísticas, epilinguisticas e metalinguisticas.

Fonte: LIMA, 2017, p. 158-159. 
$\mathrm{Na}$ organização do material, essa caixinha era destinada ao professor/leitor, isto é, não apareceria na versão do aluno. Como o propósito desse espaço era sinalizar, para esse leitor mais especializado, a relação das questões com os eixos de ensino, ele é apresentado antes do início efetivo do Módulo V. Destaca-se, nessa apresentação, que o ob- jetivo do módulo é trabalhar as formas do acusativo anafórico de terceira pessoa, considerando os contínuos de variação linguística, conforme esperado nas atividades que contemplam o Eixo III.

A Figura 1, a seguir, ilustra mais um trecho do material: exercício com o clítico acusativo.

Figura 1 - A variante clítico acusativo no material sobre a retomada do acusativo anafórico

TEXTO I

E Cabral descobriu o Brasil. Na manhã seguinte, o grumete foi acordá-lo:

- Dom Cabral, Dom Cabral, Frei Henrique de Coimbra mandou chamar o senhor para assistir à Primeira missa!

E Cabral respondeu:

- Estou muito cansado. Diga a ele que vou na das dez. (ZIRALDO. Mais anedotinhas do bichinho da maçã. Editora Melhoramento)

1) Esse texto, embora seja escrito, busca reproduzir a fala dos personagens. Isso significa que as duas modalidades se misturam. Releia as seguintes orações:

"E Cabral descobriu o Brasil. Na manhã seguinte, o grumete foi acordá-lo"

a) A forma pronominal "lo" retoma qual termo?

b) Qual é a função sintática da forma pronominal "lo"?

c) Como ficaria a segunda oração se a forma pronominal "lo" retomasse o termo "as princesas"?

d) Essas duas orações pertencem à modalidade falada ou escrita da língua?

Fonte: LIMA, 2017, p. 159.

No Exercício 1, pressupõe-se que os alunos consigam recuperar a referência de um termo pronominal (item a) - exercício linguístico (Eixo I; Eixo II) - e já reconheçam a função sintática de objeto direto (item b) exercício metalinguístico (Eixo I). Além disso, o estudante é convidado a utilizar outra forma no mesmo contexto (item c), o que representa um exercício epilinguístico (Eixo I). Ainda nessa questão, inicia-se a abordagem do continuum de oralidade-letramento (Eixo III).

As figuras 2 e 3 contêm exercícios que tratam do SN anafórico e do pronome lexical, respectivamente:

Figura 2 - A variante $S N$ anafórico no material sobre a retomada do acusativo anafórico

2) Essa notícia foi escrita a partir da reportagem veiculada pelo RJTV, programa televisivo. Nesse texto, há mistura das modalidades oral e escrita da Língua Portuguesa? Justifique sua resposta.

3) Na oração "praticava a modalidade há pouco tempo":

a) Identifique o complemento do verbo praticar.

b) Que termo está sendo retomado pelo objeto direto do verbo praticar?

Fonte: LIMA, 2017, p. 160. 
Figura 3 - A variante pronome lexical no material sobre a retomada do acusativo anafórico

4) Agora, observe a seguinte oração:

I - "Quando vi ele fazer esse esporte, na verdade eu não fiquei bem"

a) Identifique o termo que funciona como complemento do verbo ver.

b) Que termo funciona como sujeito do verbo fazer?

c) Nesse caso específico, o que é possível concluir sobre o pronome ele?

Fonte: LIMA, 2017, p. 160-161.

No exercício 2, o aluno é levado a reconhecer o sintagma nominal "a modalidade" como o termo que está retomando "speedfly" na sequência encontrada no texto ("O piloto de 'speedfly' que se acidentou ao saltar da Pedra Bonita, nesta quinta-feira (15), praticava a modalidade há pouco tempo."). Além de apontar essa forma como uma das variantes que representam o acusativo anafórico de terceira pessoa, um dos objetivos do material também é fazer com que o aluno reconheça o valor que essa forma tem enquanto recurso coesivo, a fim de evitar repetições no mesmo trecho.
Já no exercício 4, o pronome lexical é a variante em análise. 0 trecho trabalhado é uma estrutura complexa, como já caracterizada por Duarte (1986), em que o OD é representado por uma minioração ("ele fazer esse esporte. Nesse tipo de estrutura sintática, estudos mostram (cf. DUARTE. 1986; entre outros) que, no Português Brasileiro, o uso do pronome lexical é favorecido quando o termo retomado tem referente [+ animado], como "o piloto de speedfly". A escolha dessa estrutura para ilustrar o uso do pronome lexical é oportuna, visto que, especificamente nesse caso, não há estigma associado a essa forma.

Figura 4 - A variante objeto nulo no material sobre a retomada do acusativo anafórico

7) Esses dois textos apresentam mais uma estratégia para realizar o objeto direto de retomada. Releia as seguintes orações:

\section{I - "torcem o pano, molham-no novamente, voltam a torcer" \\ II - "Perguntei se ela conhecia, disse que não"}

a) Nas duas orações, identifique o termo que funciona como objeto direto dos verbos destacados.

b) De que modo esses objetos se diferenciam dos demais apresentados até agora?

Fonte: LIMA, 2017, p. 162.

Por fim, na questão 7 (Figura 4), a partir de um exercício linguístico (Eixo I), o aluno é levado a identificar a quarta forma de representação do acusativo anafórico de terceira pessoa: o objeto nulo. De todas, essa é forma que os brasileiros mais usam na fala, a despeito de não haver muita consciência desse uso, como mostram os estudos sobre o tema. Trazê-la para o contexto ensino, assim como abordar de maneira sistemática as demais formas, é uma tentativa de promover a reflexão linguística acerca dessa forma, a partir de atividades voltadas para o Eixo III, o da variação. 


\section{Considerações finais}

Indubitavelmente a escola exerce um papel importante na conscientização dos usos das diversas variantes linguísticas, sejam elas estigmatizadas ou prestigiadas. Enquanto instituição em que supostamente imperam as práticas de letramento, em geral, apenas as variantes mais prestigiadas são privilegiadas no ensino de Língua Portuguesa. A implementação dessas formas nas práticas escritas dos alunos ocorre de modo gradual, e nem sempre o aluno chega ao último ano do ensino fundamental com pleno domínio dessas formas supostamente não vernáculas, como ficou evidenciado na análise diagnóstica dos usos pronominais dos estudantes.

Muito embora o caminho a ser percorrido seja longo, a produção do material didático, apresentado em parte aqui, contribui diretamente para a construção de um repositório de materiais que, baseados no que os estudos de descrição linguística apresentam, possa servir para um ensino de Língua Portuguesa mais efetivo, ao considerar a variação linguística como estratégia para ampliar o repertório dos alunos.

0 estudo e a descrição de qualquer fenômeno linguístico variável é também interessante ao ensino de Língua Portuguesa, visto que, aos professores dessa disciplina, compete a promoção da reflexão linguística, com objetivo de ampliar o repertório linguístico dos alunos, seja para produção ou para recepção de formas alternantes. Nesse sentido, a presente investigação contribui com a descrição do comportamento do acusativo anafórico de terceira pessoa em contexto escolar.

Certamente, a exploração do acusativo anafórico de terceira pessoa não se esgota com essa investigação. Considerando que um dos objetivos da escola é promover o acesso às normas de prestígio, cumpre ain- da atualizar a descrição do comportamento do acusativo anafórico de terceira pessoa em textos jornalísticos tal atual sincronia distribuídos em um continuum de gêneros textuais -, os quais, supostamente, seriam representativos da máxima expressão da escrita culta. Tal empreendimento já vem sendo realizado por Lima (2021), em pesquisa de Doutorado em andamento.

\section{Referências}

AVERBUG, Mayra Cristina Guimarães. Objeto indireto anafórico e sujeito pronominal na escrita de estudantes. Dissertação (Mestrado). Rio de Janeiro: Faculdade de Letras/UFRJ, 2000.

AVERBUG, Mayra Cristina. Objeto Direto Anafórico: variação na produção oral e escrita e influência no ensino. In: Estudos da linguagem: atualidade \& paradoxos: Anais do VII Congresso da ASSEL, Rio de Janeiro, p. 680-687, 1998.

BARBOSA, Afrânio Gonçalves. Variação linguística no curso de Letras: práticas de ensino. In: ZILLES, Ana Maria Stahl; FARACO, Carlos Alberto. (Orgs.). Pedagogia da variação linguística: língua e diversidade. São Paulo: Parábola Editorial, 2015, p. 249-286.

BORTONI-RICARDO, Stella Maris. O Português brasileiro. In: BORTONI-RICARDO, Stella Maris. Educação em língua materna: a sociolinguística na sala de aula. São Paulo: Parábola editorial, 2004, p. 51-70.

BORTONI-RICARDO, Stella Maris. Um modelo para análise sociolinguística do português brasileiro. In: Nós cheguemu na escola, e agora? Sociolinguística e educação. São Paulo: Parábola editorial, 2005, p. 45-52.

BRASIL. Ministério da Educação. Parâmetros Curriculares Nacionais: língua portuguesa. Brasília: MEC, 1998. Disponível em: http://portal.mec.gov.br/seb/ Acesso em: 01 abr. 2021.

BRASIL. Ministério da Educação. Base Nacional Comum Curricular. Brasília: MEC, 2018. Disponível em: http://basenacionalcomum.mec. gov.br/. Acesso em: 01 abr. 2021.

CHAGAS, Danieli Silva. Concordância verbal de terceira pessoa: descrição sociolinguística e 
proposta pedagógica em turmas do ensino fundamental. Dissertação (Mestrado Profissional em Letras). Rio de Janeiro: Faculdade de Letras, UFRJ, 2016.

CYRINO, Sônia Maria Lazzarini. o Objeto Nulo no Português Brasileiro: um estudo sintático-diacrônico. Tese (Doutorado). Campinas: Unicamp, 1994.

DUARTE, Maria Eugênia Lammoglia; SERRA, Carolina Ribeiro. Gramática(s), ensino de português e adequação linguística?. Matraga, v. 22, p. 31-55. 2015.

DUARTE, Maria Eugênia Lammoglia. O papel da Sociolinguística no (re)conhecimento do Português Brasileiro e suas implicações para o ensino. Revista Letra, v. 1, p. 15-30. 2013.

DUARTE, Maria Eugênia Lammoglia. Do pronome nulo ao pronome pleno: a trajetória do sujeito no português do Brasil. In: ROBERTS, Ian; KATO, Mary Aizawa. Português brasileiro: uma viagem diacrônica. São Paulo: Contexto, 2018 [1993].

DUARTE, Maria Eugênia Lammoglia. Variação e sintaxe: clítico acusativo, pronome lexical e categoria vazia no português do Brasil. Dissertação (Mestrado). São Paulo, PUC/SP, 1986.

FARACO, Carlos Alberto. Norma culta brasileira: construção e ensino In: ZILLES, Ana Maria Stahl; FARACO, Carlos Alberto. (Orgs.). Pedagogia da variação linguística: língua e diversidade. São Paulo: Parábola Editorial, 2015, p. 249-286.

FARACO, Carlos Alberto. Norma culta Brasileira: desatando alguns nós. São Paulo: Parábola, 2008.

FARACO, Carlos Alberto. Norma culta Brasileira: construção e ensino. In: ZILLES, Ana Maria Stahl; FARACO, Carlos Alberto. (Orgs.). Pedagogia da variação linguística: língua e diversidade. São Paulo: Parábola Editorial, 2015, p. 19-30.

FREIRE, Gilson Costa. A realização do acusativo e do dativo anafóricos de terceira pessoa na escrita brasileira e lusitana. Tese (Doutorado em Letras Vernáculas). Rio de Janeiro: Faculdade de Letras/UFRJ, 2005.

FREIRE, Gilson Costa. Os clíticos de terceira pessoa e as estratégias para sua substituição na fala culta brasileira e lusitana. Dissertação (Mestrado em Letras Vernáculas). Rio de Janeiro: Faculdade de Letras/UFRJ, 2000.

GOUVÊA, Isabela Passos. Variação das formas interlocutivas de segunda pessoa: estratégias pedagógicas. Dissertação (Mestrado Profissional em Letras). Rio de Janeiro: Faculdade de Letras/UFRJ, 2016.

LABOV, William. Padrões sociolinguísticos. Trad.: Marcos Bagno; Marta Scherre e Caroline Cardoso. São Paulo: Parábola, 2008 [1972].

LIMA, Ricardo Joseh. Variação linguística e os livros didáticos de português, 2014. In: MARTINS, Marco Antonio; VIEIRA, Silvia Rodrigues; TAVARES, Maria Alice. (Orgs.). Ensino de Português e Sociolinguística. São Paulo: Contexto, 2014, p. 115-131.

LIMA, Monique Débora Alves de Oliveira. Quadro de pronomes pessoais na escola: diagnose e proposta pedagógica. Dissertação (Mestrado em Letras Vernáculas). Rio de Janeiro: Faculdade de Letras, UFRJ, 2017.

MACHADO, Ana Carla Morito. 0 uso e a ordem dos clíticos da escrita de estudantes da cidade do Rio de Janeiro. Dissertação (Mestrado em Letras Vernáculas). Rio de Janeiro: Faculdade de Letras/UFRJ, 2006.

OMENA, Nelize Pires de. Pronome pessoal de terceira pessoa: suas formas variantes em função acusativa. Dissertação (Mestrado). Rio de Janeiro: PUC/RJ, 1978.

PAULIUKONIS, Maria Aparecida Lino. Texto e contexto. In: VIEIRA, Silvia Rodrigues; BRANDÃO, Silvia Figueiredo. (Orgs.). Ensino de gramática: descrição e uso. 2. ed. São Paulo: Contexto, 2007, p. 237-258.

SANKOF, David et alii. GoldVarb-X: a variable rule application for Macintosh and Windows, 2005.

SANTANA, Juliana Magalhães Catta Preta de. Diagnose e ensino de pronomes: um estudo sobre a retomada anafórica do objeto direto de terceira pessoa no Português Brasileiro. Dissertação (Mestrado em Letras Vernáculas). Rio de Janeiro: Faculdade de Letras/UFRJ, 2016.

SOUZA, Daniela da Silva de. Estratégias de indeterminação do sujeito: uma proposta pe- 
dagógica para o ensino de gramática. Dissertação (Mestrado Profissional em Letras). Rio de Janeiro: Faculdade de Letras/UFRJ, 2015.

VIEIRA, Silvia Rodrigues. Ensino de português e o contínuo fala-escrita: o caso das estratégias de relativização. Revista PerCursos, Florianópolis, v. 18, n. 37, p. 08-35, maio/ago. 2017b.

VIEIRA, Silvia Rodrigues. Três eixos para o ensino de gramática: uma proposta experimental. In: NORONHA, Claudianny Amorim; SÁ JR., Lucrécio Araújo de. (Org.). Escola, ensino e linguagem. Natal-RN: EDUFRN, 2017a, v. 1, 78104.

VIEIRA, Silvia Rodrigues; FREIRE, Gilson Costa. Variação morfossintática e ensino de Português.
In: MARTINS, Marco Antonio; VIEIRA, Silvia Rodrigues; TAVARES, Maria Alice. (Orgs.) Ensino de Português e Sociolinguística. São Paulo: Contexto, 2014, p. 81-114.

WEINREICH, Uriel; LABOV, William; HERZOG, Marvin. Fundamentos empíricos para uma teoria da mudança linguística. Tradução: Marcos Bagno. Revisão técnica: Carlos Alberto Faraco. São Paulo: Parábola Editorial, 2006 [1968].

XAVIER, Alice Carla Marcelino. 0 acusativo anafórico e normas do Português na escola: uma proposta de intervenção para o ensino de gramática. Dissertação (Mestrado Profissional em Letras). Natal: UFRN, 2015.

Recebido em: 15/04/2021

Aprovado em: 10/08/2021 